\title{
GAMBARAN STATUS KARANG GIGI PADA PEGAWAI PUSKESMAS BATUDAA KABUPATEN GORONTALO TAHUN 2019
}

\author{
Suharni Pelealu ${ }^{1}$, Anneke Tahulending ${ }^{2}$, Vega Roosa Fione ${ }^{3}$ \\ 1) Puskesmas Batudaa Kabupaten Gorontalo \\ 2,3)Jurusan Keperawatan Gigi Poltekkes Kemenkes Manado \\ Email : pelealuharni@gmail.com
}

\begin{abstract}
ABSTRAK
Pendahuluan : Masalah kesehatan gigi dan mulut yang paling dominan adalah karang gigi. Karang gigi adalah kumpulan plak yang mengalami kalsifikasi dan melekat erat pada permukaan gigi serta objek solid lainnya di dalam mulut, sehingga gigi menjadi kasar dan terasa tebal. Penelitian ini bertujuan untuk mengetahui gambaran status karang gigi pegawai Puskesmas Batudaa Kabupaten Gorontalo tahun 2019. Metode : Penelitian ini bersifat deskriptif, dilakukan pada Minggu III bulan Juni 2019 di Puskesmas Batudaa Kabupaten Gorontalo. Populasi berjumlah 40 orang, sampel adalah total populasi, yaitu 40 orang pegawai Puskesmas Batudaa. Pengumpulan data dilakukan dengan memeriksa karang gigi dan menghitung indeks kalkulusnya. Data yan diperoleh dianalisa dengan penilaian kalkulus indeks yaitu Baik ( good), apa bila nilai diantara 0-0,6; Sedang (fair), apa bila nilai diantara 0,7-1,8; Buruk (poor), apa bila nilai diantara 1,9-3,0. Data disajikan dalam bentuk tabel distribusi frekuensi disertai penjelasan. Hasil : Hasil penelitian diketahui status karang gigi pegawai Puskesmas Batudaa kategori baik adalah 12 responden (30\%), 20 responden kategori sedang, 8 responden kategori buruk. Nilai rata-rata status karang gigi dengan indeks kalkulus sebesar 1,2 (kategori sedang). Berdasarkan jenis kelamin, status indeks karang gigi pada perempuan dalam kategori baik (30\%) dan kategori sedang (50\%), untuk kategori buruk tidak ada. Sedangkan untuk responden laki-laki status karang gigi semuanya dalam kategori buruk. Berdasarkan tingkat pendidikan, 13 responden yang berpendidikan sarjana mempunyai indeks karang gigi kategori baik, 17 responden dengan pendidikan Diploma III kategori sedang dan 2 responden dengan pendidikan SMA kategori buruk. Kesimpulan : Status karang gigi pada pegawai Puskesmas Batudaa dengan sebagian besar dalam kategori sedang (20 responden).
\end{abstract}

Kata kunci :Karang gigi, pegawai, puskesmas

\section{ABSTRACT}

Introduction: The most dominant dental and oral health problem is calculus. Calculus is a collection of plaques that have calcified and is firmly attached to the surface of the teeth and other solid objects in the mouth, so the teeth become rough and feel thick. This study aims to determine the description of the status of calculus employees of Gorontalo District Batudaa Health Center in 2019. Method: This research is descriptive in nature, conducted on the third week of June 2019 at Batudaa Health Center, Gorontalo Regency. The population is 40 people, the sample is the total population, that is 40 employees of the Batudaa Community Health Center. Data collection was carried out by examining calculusr and calculating its calculus index. The data obtained were analyzed by assessing the index calculus which is Good, what if the value is between 0-0.6; Medium (fair), what if the value between 0.7-1.8; Poor (poor), what if the value is between 1.9-3.0. Data is presented in the form of a frequency distribution table with an explanation. Results: The results of the study found that the status of calculus at the Batudaa Community Health Center in the good category was 12 respondents (30\%), 20 respondents were in the moderate category, 8 respondents were in the bad category. The average value of calculus status with calculus index of 1.2 (medium category). Based on sex, the 
status of calculus index in women is in the good category (30\%) and the moderate category (50\%), for the bad category does not exist. Whereas for male respondents calculus status was all in the bad category. Based on the level of education, 13 respondents with a bachelor's education had a good category of calculus, 17 respondents with a Diploma III education were in the medium category and 2 respondents with a high school education were in the poor category. Conclusion: The status of calculus in Batudaa Community Health Center employees is mostly in the medium category (20 respondents).

Keywords: calculus, employee, health center

\section{PENDAHULUAN}

Kesehatan gigi dan mulut adalah bagian dari kesehatan tubuh yang tidak dapat dipisahkan satu dengan yang lainnya sebab kesehatan gigi dan mulut akan mempengaruhi kesehatan tubuh. Pemeliharaan kesehatan gigi dan mulut merupakan salah satu upaya dalam meningkatkan kesehatan gigi dan mulut. ${ }^{1}$ Di Provinsi Gorontalo berdasarkan RISKESDAS tahun 2013 ditemukan bahwa 96,1\% orang Gorontalo menyikat gigi setiap hari, namun hanya ada 6,0\% dari keseluruhan yang menyikat gigi dengan benar. Penduduk Gorontalo yang bermasalah kesehatan gigi dan mulut pada tahun 2013 ditemukan 30,1\%. ${ }^{2}$ Berdasarkan data Dinas Kesehatan Kabupaten Gorontalo bahwa laporan data kesakitan penyakit saluran cerna (penyakit gigi dan mulut) triwulan II tahun 2013 menunjukkan 1833 penduduk rentang usia 1 bulan sampai $>70$ tahun menderita penyakit gigi dan mulut sedangkan pada triwulan III tahun 2013 terjadi kenaikan prevalensi sebesar 2718 penduduk menderita penyakit gigi dan mulut. Dimana rentang usia 514 tahun pada triwulan II tahun 2013 yang menderita penyakit gigi dan mulut sebanyak 264 orang sedangkan pada triwulan III terjadi kenaikan prevalensi sebesar 479 orang penderita. Adanya ketidaknyamanan dan kondisi menyimpang pada gigi dan mulut dapat mempengaruhi status kesehatan setiap orang. 3
Masalah kesehatan gigi dan mulut yang paling dominan adalah karang gigi. Karang gigi adalah kumpulan plak yang mengalami kalsifikasi dan melekat erat pada permukaan gigi serta objek solid lainnya di dalam mulut, sehingga gigi menjadi kasar dan terasa tebal. Terjadinya karang gigi yaitu adanya plak dan adanya sisa-sisa makanan sehingga lama kelamaan terbentuk karang gigi. Ciri-ciri dari karang gigi yaitu, permukaannya keras dan kasar, warnanya putih kekuning-kuningan dan sampai coklat kehitaman. Akibat dari karang gigi adalah gusi mudah berdarah, gusi berwarna merah, bau mulut dan gigi mudah goyang.Apabila tidak dirawat dapat menyebabkan kehilangan gigi. Studi epidemiologi menunjukkan bahwa karang gigi dapat dicegah dengan pembersihan plak yaitu dengan sikat gigi teratur sehingga tidak terbentuk karang gigi. ${ }^{4}$

Karang gigi hanya bisa dibersihkan dengan bantuan dokter gigi dan tenaga kesehatan gigi. Pergi ke dokter bukan hanya ketika mengalami sakit. Jika gigi mulai mengalami plak, maka lebih baik mencegah dari pada mengobati. Oleh karena itu kontrol atau periksa ke dokter gigi, ke poliklinik gigi rumah sakit atau puskesmas setiap 6 bulan sekali untuk memeriksakan kesehatan gigi dan mulut. ${ }^{5}$

Puskesmas Batudaa merupakan salah satu puskesmas rawat inap dengan tingkat kunjungan pasien tertinggi diantara puskesmas lainnya. Hal 
ini karena jumlah penduduk di kecamatan Batudaa cukup banyak yaitu berjumlah sekitar 14.566 jiwa yang terdiri dari laki-laki berjumlah 7.391 dan penduduk perempuan dengan jumlah 7.298 jiwa dari delapan desa yang ada di kecamatan Batudaa, dengan jumlah penduduk miskin sebanyak 10.000 jiwa (profil puskesmas, 2016). Selain itu, karena layanan Puskesmas sudah cukup lengkap ditambah dengan jumlah pegawai yang memadai, menyebabkan banyak kunjungan pasien pada puskesmas ini. Pelayanan prima pada pasien oleh pegawai puskesmas Batudaa harus optimal, agar pasien benar-benar terlayani dan merasa puas dan setiap pegawai berkewajiban memelihara kesehatan dirinya sendiri, termasuk menjaga kebersihan mulutnya terutama perawatan gigi dari karang gigi. ${ }^{6}$

Berdasarkan hasil survei awal yang dilakukan pada 10 orang pegawai Puskesmas Batudaa, diketahui bahwa rata-rata nilai indeks kalkulus adalah 1,56. Menurut Green dan Vermilion, nilai ini termasuk dalam kategori sedang. Selain itu, ada dua orang yang termasuk dalam kategori buruk, tujuh orang termasuk kategori sedang, dan hanya satu orang termasuk kategori baik. Dari hasil tanya jawab dengan responden, paling banyak menjawab tidak tahu tentang karang gigi, penyebab serta akibat yang ditimbulkan karang gigi. Begitu juga dengan kegiatan menyikat gigi, semua menjawab bahwa mereka menyikat gigi hanya pada saat mandi saja, tidak menyikat gigi sehabis makan dan sebelum tidur.

Penelitian ini bertujuan untuk mengetahui gambaran status karang gigi pada pegawai puskesmas Batudaa Kabupaten Gorontalo.

\section{METODOLOGI}

Penelitian ini menggunakan metode penelitian survei deskriptif dengan pendekatan Cross Sectional yaitu suatu penelitian dengan cara pengamatan, observasi atau pengumpulan data sekaligus pada suatu saat.

Penelitian ini dilakukan di Puskesmas Batudaa Kecamatan Batudaa Kabupaten Gorontalo pada Minggu III bulan Juni 2019.

Variabel dalam penelitian ini mono variabel (hanya satu variabel) yaitu karang gigi pada pegawai Puskesmas Batudaa.

\section{Definisi operasional :}

1. Karang gigi adalah suatu endapan keras yang melekat pada permukaan gigiyang berwarna putih kekuningan dan hijau kecoklatan. Penilaian karang gigi menggunakan Indeks Kalkulus (CI) dengan kriteria penilaian Baik (good) apabila nilai berada diantara $0-0,6$; Sedang (fair), apabila nilai berada diantara $0,7-1,8$; Buruk (poor), apabila nilai berada diantara $1,9-3,0$.

2. Pegawai adalah orang yang aktif bekerja dan yang tercatat sebagai pegawai baik PNS maupun honorer yang bekerja pada Puskesmas Batudaa Kabupaten Gorontalo.

Populasi dalam penelitian ini adalah semua pegawai Puskesmas Batudaa Kecamatan Batudaa Kabupaten Gorontalo berjumlah 40 orang dan Sampel pada penelitian ini adalah total populasi

Data yang didapat ditabulasi dan disajikan dalam bentuk tabel distribusi frekuensi.

\section{HASIL}

Puskesmas Batudaa Kecamatan Batudaa berdiri sejak tahun 1954, pada saat itu membawahi wilayah Batudaa, Batudaa Pantai dan Bongomeme. Seiring perjalanan waktu dan kebutuhan masyarakat akan pelayanan kesehatan serta pengembangan daerah, pemerintah daerah melakukan pemekaranpemekaran wilayah sehingga pada saat ini 
Puskesmas Batudaa hanya tinggal memiliki wilayah kecamatan Batudaa yang terdiri dari 8 (delapan) desa, 34 dusun. Pada tahun 2008, Puskesmas Batudaa menjadi Puskesmas Medical Centre yang bisa melalukan pelayanan rawat inap. Kemudian tahun 2009, Puskesmas Batudaa meningkat statusnya menjadi Puskesmas Poned dan pada tahun 2011 ditetapkan sebagai Puskesmas Global.

Tabel 1.Distribusi Ketenagaan Berdasarkan Jenis Kelamin

\begin{tabular}{cccc}
\hline No & $\begin{array}{c}\text { Jenis } \\
\text { Kelamin }\end{array}$ & Jumlah & $\begin{array}{c}\text { Prosentase } \\
(\%)\end{array}$ \\
\hline 1 & Laki-laki & 8 & 20 \\
2 & Perempuan & 32 & 80 \\
\hline & Jumlah & 40 & 100 \\
\hline
\end{tabular}

Pada tabel 1 terlihat bahwa sebagian besar responden adalah perempuan yaitu $80 \%$ sedangkan responden laki-laki hanya $20 \%$.

Tabel 2. Distribusi Responden Berdasarkan Tingkat Pendidikan

\begin{tabular}{clcc}
\hline No & \multicolumn{1}{c}{$\begin{array}{c}\text { Tingkat } \\
\text { Pendidikan }\end{array}$} & Jumlah & $\begin{array}{c}\text { Prosentase } \\
(\%)\end{array}$ \\
\hline 1 & Sarjana (S1 dan & 13 & 32,5 \\
& D4) & 17 & 42,5 \\
2 & Diploma Tiga & 10 & 25 \\
3 & SMA & 40 & 100 \\
\hline \multicolumn{2}{r}{ Jumlah } \\
\hline
\end{tabular}

Berdasarkan tabel 2 menunjukkan bahwa tingkat pendidikan dari responden sebagian besar adalah Diploma tiga yaitu 17 responden $(42,5 \%)$, Sarjana berjumlah 13responden $(32,5 \%)$ dan SMA 10 responden $(25 \%)$.

Tabel 3. Distribusi status karang gigi responden

\begin{tabular}{clcc}
\hline & \multicolumn{2}{c}{ Status Indeks } & Persentase \\
No & \multicolumn{1}{c}{ Karang Gigi } & Jumlah & \\
\hline 1 & Baik & 12 & 30 \\
2 & Sedang & 20 & 50 \\
3 & Buruk & 8 & 20 \\
\hline & Jumlah & 40 & 100 \\
\hline
\end{tabular}

Berdasarkan tabel diatas, dapat dilihat status indeks karang gigi kategori baik adalah sebanyak 12 pegawai (30\%), 20 pegawai dengan kategori sedang atau sekitar 50\%, dan 8 pegawai dengan kategori karang gigi buruk atau sekitar 20\%. Berdasarkan hasil pemeriksaan nilai rata-rata status karang gigi pada responden Puskesmas Batudaa adalah sebesar 1,2 sehingga termasuk dalam kategori sedang

Tabel 4. Distribusi status karang gigi berdasarkan jenis kelamin

\begin{tabular}{|c|c|c|c|c|c|c|c|c|}
\hline \multirow{2}{*}{ Jenis kelamin } & \multicolumn{7}{c|}{ Status Indeks Kalkulus } \\
\cline { 2 - 10 } & \multicolumn{2}{|c}{ Baik } & \multicolumn{2}{c|}{ Sedang } & \multicolumn{2}{c|}{ Buruk } & \multicolumn{2}{c|}{ Total } \\
\cline { 2 - 10 } & $\mathbf{n}$ & $\mathbf{\%}$ & $\mathbf{n}$ & $\mathbf{\%}$ & $\mathbf{n}$ & $\mathbf{\%}$ & $\mathbf{n}$ & $\mathbf{\%}$ \\
\hline Laki-Laki & 0 & 0 & 8 & 20 & 8 & 20 & 8 & 20 \\
\hline Perempuan & 12 & 30 & 0 & 0 & 0 & 0 & 32 & 80 \\
\hline Total & $\mathbf{1 2}$ & $\mathbf{3 0}$ & $\mathbf{8}$ & $\mathbf{2 0}$ & $\mathbf{8}$ & $\mathbf{2 0}$ & $\mathbf{4 0}$ & $\mathbf{1 0 0}$ \\
\hline
\end{tabular}

Berdasarkan tabel 4, dapat dilihat bahwa pada semua responden laki-laki berjumlah 8 orang (20\%) memiliki status indeks karang gigi buruk. Pada responden perempuan yang mempunyai status indeks karang gigi baik adalah sebanyak 12 pegawai $(30 \%)$, kategori sedang sebanyak 20 pegawai $(50 \%)$, dan tidak ada pegawai perempuan dengan status indeks karang gigi yang buruk.

Tabel 5. Distribusi status karang gigi responden berdasarkan tingkat pendidikan

\begin{tabular}{|c|c|c|c|c|c|c|c|c|}
\hline \multirow{3}{*}{ Pendidikan } & \multicolumn{6}{|c|}{ Status Indeks Karang Gigi } & \multirow{2}{*}{\multicolumn{2}{|c|}{ Total }} \\
\hline & \multicolumn{2}{|c|}{ Baik } & \multicolumn{2}{|c|}{ Sedang } & \multicolumn{2}{|c|}{ Buruk } & & \\
\hline & $n$ & $\%$ & $n$ & $\%$ & $\mathrm{n}$ & $\%$ & $\mathrm{n}$ & $\%$ \\
\hline Sarjana (S1 dan D4) & 13 & 32.5 & 0 & 0 & 0 & 0 & 13 & 32.5 \\
\hline Diploma Tiga & 0 & 0 & 17 & 42.5 & 0 & 0 & 17 & 42.5 \\
\hline SMA & 0 & 0 & 2 & 5 & 8 & 20 & 10 & 25 \\
\hline Total & 13 & 32.5 & 19 & 47.5 & 8 & 20 & 40 & 100 \\
\hline
\end{tabular}


Pada tabel 5, dapat dilihat bahwa responden dengan pendidikan Sarjana (S1 dan D4) mempunyai status indeks karang gigi dalam kategori baik sebanyak 13 pegawai atau sekitar 32,5\%, kategori sedang terdiri dari pegawai dengan pendidikan DIII sebanyak 17 pegawai atau sekitar $42,5 \%$ dan responden yang berpendidikan SMA status indeks karang gigi kategori sedang 2 orang dan buruk sebanyak 8 orang.

\section{PEMBAHASAN}

Karang gigi merupakan salah satu masalah paling dominan yang terjadi pada seluruh lapisan masyarakat. Begitu juga dengan pegawai Puskesmas Batudaa, permasalahan ini dapat berpengaruh pada pelayanan pasien sehingga dapat mengganggu kesehatan pegawai sebagai petugas kesehatan bahkan juga berpengaruh terhadap kenyamanan pasien.

Berdasarkan penelitian ini yang dilakukan pada 40 pegawai Puskesmas Batudaa diketahui bahwa status indeks karang gigi kategori baik adalah sebanyak 12 responden (30\%), 20 responden dengan kategori sedang atau sekitar $50 \%$, dan 8 responden dengan kategori karang gigi buruk atau sekitar 20\%. Hasil pemeriksaan karang gigi berdasarkan jenis kelamin yaitu diketahui bahwa semua responden laki-laki memiliki status indeks karang gigi buruk, sedangkan pada perempuan untuk status indeks karang gigi kategori baik adalah sebanyak 12 responden (30\%), kategori sedang sebanyak 20 responden (50\%), dan tidak ada responden perempuan dengan status indeks karang gigi yang buruk.

Hasil penelitian ini menunjukkan bahwa status karang gigi dengan kategori buruk ada pada responden laki-laki, sedangkan kategori sedang dan baik ada pada responden perempuan. Natamihardja,2008 menyatakan bahwa salah satu faktor yang mempermudah (predisposing factor) dan mendasari untuk terjadinya perubahan perilaku pada seseorang dipengaruhi oleh jenis kelamin. Dalam hal pelihara diri, perempuan masih lebih memperhatikan estetika gigi dan penampilan di dalam pergaulan di masyarakat dibandingkan dengan laki-laki. Selain itu, faktor lain yang mengindikasikan kurangnya pelihara diri pada sebagian lakilaki yaitu kebiasaan merokok. ${ }^{7}$

Menurut Sumerti (2016) dalam jurnalnya tentang merokok dan efeknya terhadap kesehatan gigi dan mulut menjelaskan bahwa kandungan pada rokok salah satunya tar dapat menyebabkan penodaan pada gigi, permukaan gigi akan menjadi kasar dan mempercepat akumulasi plak. Plak ini jika tidak dikendalikan dengan baik, maka timbunan bakteri dalam plak akan semakin banyak kemudian mengalami pertambahan massa dan terjadi pengerasan yang disebut karang gigi. Hal ini menyebabkan status karang gigi pada lakilaki perokok ada dalam kategori buruk. ${ }^{8}$

Gambaran persentase status karang gigi berdasarkan pendidikan responden Puskesmas Batudaa yaitu status indeks karang gigi kategori baik terdiri dari responden dengan pendidikan Sarjana yaitu sebanyak 13 pegawai atau sekitar 32,5\%, kategori sedang terdiri dari responden dengan pendidikan Diploma III sebanyak 17 pegawai atau sekitar $42,5 \%$ dan 2 responden dengan pendidikan SMA atau sekitar 5\%, kategori buruk dimiliki oleh responden SMA sebanyak 8 orang atau sekitar $20 \%$.

Pada hasil penelitian didapatkan tingkat pendidikan memiliki pengaruh terhadap indeks karang gigi, karena pada penelitian ini diketahui indeks karang gigi paling baik terdapat pada tingkat pendidikan S1 dan indeks karang gigi paling buruk terdapat pada tingkat pendidikan SMA. Hal ini sesuai dengan Penelitian Pintauli (2004 yaitu seseorang yang memiliki tingkat pendidikan rendah kemungkinan akan memiliki pengetahuan yang kurang mengenai kesehatan gigi dan mulut. Pendidikan sebagai sistem mempunyai 
pengaruh dalam pembentukan sikap dikarenakan keduanya meletakan dasar pengertian dan konsep moral dalam diri individu, pemahaman yang baik dan buruk, boleh atau tidak boleh dilakukan. Semakin tinggi pendidikan seseorang, maka orang tersebut akan memiliki pemahaman yang lebih baik sehingga akan berpengaruh terhadap sikap. ${ }^{9}$

Perbedaan tingkat pendidikan berpengaruh terhadap kecenderungan orang menggunakan pelayanan kesehatan sehubungan dengan variasi mereka dalam pengetahuan mengenai kesehatan gigi. Kurangnya pengetahuan mengenai kesehatan gigi dan ketidaktahuan akan bahaya penyakit gigi karena rendahnya tingkat pendidikan akan menyebabkan masyarakat tidak memanfaatkan pelayanan kesehatan gigi yang ada. Menurut Said (2011), pendidikan seseorang dapat mempengaruhi tingkat kebersihan gigi dan mulutnya, seseorang yang pendidikannya rendah mempunyai pengetahuan yang kurang dalam memelihara kebersihan gigi dan mulutnya. Berbeda dengan orang yang lebih tinggi kemampuan dalam menjaga kebersihan gigi dan mulutnya lebih tinggi karena mereka lebih memperhatikan kondisi mulutnya. ${ }^{10}$

\section{KESIMPULAN}

Dari hasil penelitian, dapat disimpulkan sebagai berikut :

1. Status karang gigi pada pegawai Puskesmas Batudaa dengan kategori baik adalah sebanyak 12 responden, 20 responden dengan kategori sedang dan 8 responden dengan kategori karang gigi buruk atau sekitar 20\%. Nilai rata-rata status karang gigi pada responden Puskesmas Batudaa adalah sebesar 1,2 sehingga termasuk dalam kategori sedang.

2. Berdasarkan jenis kelamin, status indeks karang gigi pada responden perempuan pada umumnya dalam kategori baik (30\%) dan kategori sedang (50\%), untuk kategori buruk tidak ada. Sedangkan untuk responden laki-laki status karang gigi semuanya dalam kategori buruk.

3. Berdasarkan tingkat pendidikan, sekitar 13 responden yang berpendidikan sarjana mempunyai indeks karang gigi dalam kategori baik, 17 responden dengan pendidikan Diploma III dalam kategori sedang dan 2 responden dengan pendidikan SMA kategori buruk.

\section{DAFTAR PUSTAKA}

1. Ghofur, A. (2012). Buku Pintar Kesehatan Gigi dan Mulut. Mitra Buku. Yogyakarta

2. Kementerian Kesehatan RI., 2013. Riset Kesehatan Dasar, Badan Penelitian \& Pengembangan Tenaga Kesehatan Kemenkes. Laksana, Jakarta

3. Profil Dinas Kesehatan Kabupaten Gorontalo. (2013)

4. Putri, M.H. 2011.Ilmu Pencegahan Penyakit Keras dan Jaringan Pendukung Gigi.EGC. Jakarta

5. Margareta, S. (2012). 101 tips \& terapi alami agar gigi putih \& sehat. Pustaka Cerdas. Yogyakarta.

6. Profil Puskesmas Batudaa. (2016)

7. Natamiharja L, Hiskia Z, Dorlina (2008). Pengalaman karies gigi, status periodontal dan perilaku oral hygiene pada siswa kelas VI SD, kelas III SMP, dan kelas III SMA kecamatan Medan Baru. Dental Journal. 2008;13(2):131-2

8. Sumerti I.N, 2016. Merikok dan Efeknya Terhadap Kesehatan Gigi dan Rongga Mulut. Jurnal Kesehatan Gigi Poltekkes Denpasar Vo. 4 No. 2 Agustus 2016.

9. Pintauli S, Melur T. (2004). Hubungan tingkat pendidikan dan skor DMF-T pada ibu-ibu rumah tangga berusia 20-45 
tahun di Kecamatan Medan Tuntungan.

Dentika dent J. 2004; 9(2): 78-83.

10. Said F, Ida R, Sri H, Rina H. (2011).

Hubungan perilaku memelihara gigi dengan penyakit pulpa pada pasien di poliklinik gigi puskesmas Sungkai Kalimantan Selatan. Banjarmasin: Kesehatan Gigi Poltekkes Kemenkes Banjarmasin. 2011; 4(1): 5-7. 